\title{
What are teens doing with media? An ethnographic approach for identifying transmedia skills and informal learning strategies
}

\author{
Carlos A. Scolari \\ carlosalberto.scolari@upf.edu \\ Universitat Pompeu Fabra - Barcelona \\ Elisenda Ardèvol \\ eardevol@uoc.edu \\ Universitat Oberta de Catalunya \\ Òliver Pérez-Latorre \\ oliver.perez@upf.edu \\ Universitat Pompeu Fabra - Barcelona \\ Maria-Jose Masanet \\ mjose.masanet@ub.edu \\ Universitat de Barcelona \\ Nohemi Lugo Rodríguez \\ nlugo@itesm.mx \\ ITESM Querétaro
}

\begin{abstract}
The emergence of new media, devices, narratives and practices has compelled media literacy scholars and professionals to review their theoretical frameworks and methodological approaches. Based on a new conception - 'transmedia literacy' - that moves from traditional media literacy to informal learning and participatory culture practices, the research program behind the present article aims to understand how new generations are doing things with media outside schools and how they learnt to do the things they do. The article begins by describing the transformations of media literacy in recent years as a consequence of the mutations of the media ecology and, in that context, proposes a methodological approach for analysing the acquisition of transmedia skills by teens in informal learning environments. The article describes, analyses and evaluates the development and initial implementation of this methodology working with teenagers in a high-school in Barcelona. It ends with a Research Kit that includes surveys, creative workshops, interactive interviews and media diaries with teens between 12-18 years old. The article also describes the evolution of this methodological approach from its original formulation to the evaluation of the model after it was tested, and reflects on the possibilities of developing specific research devices to be applied in transnational research.
\end{abstract}

\section{Keywords}

Transmedia literacy; media literacy; ethnography; transmedia skills; informal learning strategies 


\section{Introduction: New Literacies, Transmedia Skills and Informal Learning Strategies}

Since the diffusion of personal computing in the 1980s and the expansion of the Web in the 1990s, digital technology has been a catalyst for social change in contemporary societies. Many researchers, institutions and professionals argue that while the media system has adopted and adapted to new digital technologies, schools still perceive the 'digital transition' as a traumatic process (EAVI/DTI/OII, 2011). Although schools have made great efforts to adapt to the new socio-technical conditions in the past two decades, the general perception is that the social life of children, pre-teens and teens is built up around a set of digital technologies - from social media to mobile devices - and new practices that are frequently very different from the educational protocols of schools. According to Castells (2007) there is still a cultural and technological gap between today's youth and a school system that has not evolved along with society and the digital environment: 'the idea that today a young person must load a backpack of boring text books set by ministerial bureaucrats, and must remain closed in a classroom to support an irrelevant speech in the name of his/her future, is simply absurd' (Castells, 2007: 25). Even if the situation may vary from country to country, from region to region, from cities to rural areas or from public schools to private ones, Castells' analysis is not far from the reality of many educational institutions.

The vast diffusion of digital technologies and new media practices has led to the emergence of new conceptions in the academic and professional conversations about media literacy. As Meyers, Erickson and Small (2013) put it, it is necessary to make a 'critical turn to the examination of digital literacies, de-emphasizing skills and refocusing attention on diverse contexts of use, and the emergent modes of assessment that are ground by specific circumstances and communities of practice' (360). According to Livingstone (2004), research 'must investigate the emerging skills and practices of new media users as the meaningful appropriation of ICT into their daily lives [...] A topdown definition if media literacy, developed from print and audio-visual media, while a useful initial guide, should not pre-empt learning from users themselves' (11). The emergence of new concepts runs parallel to the emergence of new theoretical frameworks and research methodologies. While in 2006 Buckingham asked, 'What do young people need to know about digital media?'; the Transmedia Literacy Project, on which this article is based, asks, "What are teens doing with media and how do they learn to do it?". Therefore, the main objective of our project was to identify the 'transmedia skills' and 'informal learning strategies' that teenagers put into practice in informal environments and how to introduce them into formal education settings. The project involved an interdisciplinary team from eight countries in Latin America, Europe and Oceania.

The concepts of 'transmedia skills' and 'informal learning strategies' are therefore at the centre of this research project. Identifying and measuring digital skills has become an important area of inquiry related to education (for example: Ferrés and Piscitelli, 2012; Jenkins et al., 2006; Livingstone \& Haddon, 2009). Activities like navigating a browser, searching for information, or downloading files are now considered basic digital skills (Hargittai, 2002; Potosky, 2007). With the growth of the Internet, scholars have proposed additional skills, such as the ability to determine other users' credibility, communicate with others, manage one's personal digital profile (Papacharissi, 2010), understand and negotiate social norms (Haythornthwaite, 2007; Knobel and Lankshear, 2008), and create and consume content (van Dijck, 2005; van Deursen, and van Dijck, 2010). In this context transmedia skills are understood as a series of advanced competences related to digital interactive media production and consumption (Jenkins, 2006; Jenkins et al., 2006; Manovich, 2009). Transmedia skills range from problem-solving processes in videogames to content production and sharing in web platforms and social media, as well as narrative content (fanfiction, fanvids, etc.) produced in digital networks (Scolari, 2018). 
In terms of informal learning strategies, in this research the team focused on how teens are learning transmedia skills outside school. It is not easy to analyse these informal learning practices. These 'wild' experiences are often invisible or directly rejected by (adult) researchers: 'So much is projected onto youth that it is often difficult to discuss what they are doing, and why, without observation being obscured by ideas of what they should or shouldn't be doing. Youth are rarely seen as deserving any agency and, yet, they are also judged based on what they choose to do [...] people think that they know something about youth either because they were once young or because they are parents to a young person' (boyd, 2014:34).

However, there are outstanding precedents in the research into young people's digital media skills. For example, in $\mathbf{2 0 0 6}$ the Future Lab published a review of the informal learning practices that take place outside schools to 'map out the different approaches to understanding how young people may be learning with ICTs in a range of settings outside the school - especially in contexts not traditionally associated with education' (Sefton-Green, 2006: 5). The review focused on the use of digital resources that are viewed as leisure activities and which are perceived by formal educational establishments as outside the realm of valued educational experience (i.e. playing computer games, using chat rooms, using digital media and digital television, etc.). According to Jenkins et al. (2006) many transmedia skills (playing, performing, navigating, etc.) are being acquired by young people through their participation in the informal learning communities that surround popular culture. Even if some teachers and after-school programs are incorporating some of these skills into their instruction and activities, 'the integration of these important social skills and cultural competencies remains haphazard at best. Media education is taking place for some youth across a variety of contexts, but it is not a central part of the educational experience of all students' (Jenkins et al., 2006: 56-57).

In this vein, the main objective of the Transliteracy project was to identify and describe adolescents' and young people's transmedia skills and informal learning strategies related to digital media by developing and applying a qualitative methodology. Our aim in this article is to present this methodology and how it was implemented and tested in a pilot experience. Therefore, we do not give our research results here (see Scolari, 2018), but rather explain the methodological framework we used and how we tested it in order to discuss its affordances and inspire new paths of adapting qualitative methods to media education research. We detail the methodological tools designed and tested in the pilot experience to explore and understand what teens are doing with media and how they learn to do it. After introducing the concept of 'transmedia literacy' (TML) (Section 2), the article describes, analyses and evaluates the first implementation of this methodology - that included questionnaires, workshops, interviews and media diaries, and online observation - working with 18 teens between 14 and 16 years old in a working class high-school in Barcelona (Section 3).

Our methodological approach aims to answer the following questions: How can we get to know teens' transmedia practices? How can we identify transmedia skills developed outside the formal learning environment? How can we identify informal learning strategies? And what combination of data gathering techniques is most useful for achieving these objectives?

As we planned to conduct the research in eight countries, the Barcelona pilot experience was helpful for establishing a first contact with teens, testing the methodology and developing a flexible Researcher's Kit to be applied in different situations and local realities. In the last section the article evaluates the methodological testing and reflects on the possibilities of this kind of approach. 


\section{From Media Literacy to Transmedia Literacy (TML)}

The changes in the media ecology and the transition from a broadcast-centred to a networkcentred system (Scolari, 2008, 2009) have unlocked the discussion about the pertinence of traditional definitions of media literacy and the emergence of new literacies. Is it still possible to talk about 'media literacy' in a context where the broadcasting (one-to-many) model is being displaced by the network (many-to-many) communication paradigm? As early as 1993, researchers like Buckingham opened the debate about the new literacies. Buckingham detected a 'blurring of boundaries between texts and between media' and exemplified the situation with computer games based on a 'trans-media intertextuality' (1993: 25). In the same text Buckingham upheld the "need for a new definition of literacy [...] not tied to particular technologies or practices' but rather one that 'allows us to look at the competencies that are developed across the whole range of culture and communication' (1993: 20).

Beyond the different possible definitions of the 'new literacies', it is clear that media literacy can no longer be limited to the critical analysis of media contents or the acquisition of media skills inside the formal education system. Many traditional media consumers are now prosumers (a concept introduced by Toffler, 1980) or produsers (Bruns, 2008), active subjects who create new contents and share them in the digital networks. Researchers of new media literacy have identified a set of competencies defined as 'prosuming skills', which include the skills necessary to produce/create media contents, from the ability to set up an online communication account to using software to generate digital contents and programming. These skills often work together with distribution, remixing and participation skills (Lin, Li, Deng, and Lee, 2013). It is in this context that the concept of TML can enrich the traditional concept of media literacies and reposition the theoretical approaches to the new literacies. TML could be understood as a set of skills, practices, values, priorities, sensibilities, and learning/sharing strategies developed and applied in the context of the digital participatory cultures. If traditional literacy was book-centred or, in the case of media literacy, mostly television-centred, then transmedia literacy places digital networks and interactive media experiences at the centre of its analytical program. TML does not conceive the subject as a passive spectator: the subject is an active prosumer (producer + consumer) who has developed their transmedia skills outside school, in informal learning environments. These informal learning spaces will be a key component of TML research.

The following table summarizes these three conceptions of 'literacy': the original conception focuses on reading and writing; the second conception is based on the (negative) effects of mass media; and the third conception is inspired by the mutations of the new media ecology and the emergence of transmedia practices.

\begin{tabular}{|c|c|c|c|}
\hline $\begin{array}{l}\text { Media semiotics } \\
\text { (language) }\end{array}$ & $\begin{array}{l}\text { Literacy } \\
\text { - Verbal text } \\
\text { (read/write) }\end{array}$ & $\begin{array}{l}\text { Media Literacy } \\
\text { - } \quad \text { Multimodal } \\
\text { (audiovisual media) }\end{array}$ & $\begin{array}{l}\text { Transmedia Literacy } \\
\text { - } \quad \text { Multimodal } \\
\text { (interactive media and } \\
\text { transmedia) }\end{array}$ \\
\hline Media supports & $\begin{array}{l}\text { - } \text { Books and } \\
\text { printed texts }\end{array}$ & - $\quad$ Broadcasting & - $\quad$ Digital networks \\
\hline $\begin{array}{l}\text { Subject } \\
\text { interpellation }\end{array}$ & - $\quad$ As an illiterate & $\begin{array}{l}\text { - As a passive } \\
\text { spectator }\end{array}$ & - As a prosumer \\
\hline $\begin{array}{l}\text { Learning } \\
\text { environment }\end{array}$ & - $\quad$ Formal (schools) & - $\quad$ Formal (schools) & $\begin{array}{l}\text { Informal (outside } \\
\text { schools) }\end{array}$ \\
\hline $\begin{array}{l}\text { Research } \\
\text { objectives }\end{array}$ & $\begin{array}{l}\text { - To analyse the } \\
\text { written-word } \\
\text { learning process }\end{array}$ & $\begin{array}{l}\text { - To analyse the } \\
\text { effects of media on } \\
\text { subjects }\end{array}$ & $\begin{array}{ll}\text { - } & \text { To identify } \\
\text { transmedia skills } \\
\text { - } \quad \text { To analyse informal }\end{array}$ \\
\hline
\end{tabular}




\begin{tabular}{|l|l|ll|l|}
\hline & $\begin{array}{l}\text { To identify the } \\
\text { literacy level of } \\
\text { society }\end{array}$ & $\begin{array}{l}\text { To identify the } \\
\text { media literacy level } \\
\text { of society }\end{array}$ & learning strategies \\
Theoretical & $\begin{array}{l}\text { Linguistics } \\
\text { references }\end{array}$ & $\begin{array}{l}\text { Media Studies } \\
\text { Cognitive } \\
\text { Sciences }\end{array}$ & $\begin{array}{l}\text { (Theory of media } \\
\text { effects) }\end{array}$ & Cultural Studies \\
\hline
\end{tabular}

Table 1: Literacy, media literacy and transmedia literacy (based on Scolari, 2016)

\section{Methodological Approach}

As explained above, the aim of the Transmedia Literacy research project was to explore transmedia skills and learning strategies that are specific to the lifestyles of contemporary youth, and particularly to teenagers in their everyday life. Specifically, the team focused on teen-centred practices of videogaming, media sociality and creative digital production that are meaningful for teenagers. These practices included teens' own ways of learning and doing, as well as their aspirations, interests, and passions and how they look for and find information, learn to play a new game, create texts, photographs and videos, what they do to improve their skills, what they are interested in, what they share, and from whom they learn. To achieve the Transmedia Literacy goals, the first step was to define the methodological approach and tools we would use to explore the transmedia skills that teens develop in informal learning environments (Pink and Ardèvol, 2018). In this section we will explain the different steps and processes carried out: the strategies used to approach our study subjects (adolescents); the definition and delimitation of the spaces where the fieldwork could be carried out; the design of the data collection tools; the evaluation of the effectiveness of these tools; and, finally, the reflection on the possibilities of our approach and tools. The main question that guided our methodological approach was then, how can researchers get to know and analyse what young people are doing with digital interactive media? Therefore, in order to empirically identify, describe and analyse the different sets of skills, we decided to focus on observable practices and youth self-explanation about their practices, according to a qualitative and ethnographic approach.

The ethnographic approach is a well-established methodology in youth and media studies (boyd, 2014; Horst, Herr-Stephenson and Robinson, 2010; Lange and Ito, 2010; Leander, 2008), and thus the team used this strategy, based on the actor's perspective and the researcher's immersion in the research context, to explore teenagers' universes and determine singularities and similarities in their patterns and models of engaging with media use and production.

As the research was to be conducted in eight countries, Barcelona's team was in charge of developing and testing a methodological kit that included research guidelines and protocols for the rest of the local national teams. One of the first methodological issues raised was how to 'get into the field': How do we reach the teens? How do we define the fieldwork settings? The first idea was that the fieldwork would take place across various online and offline settings, allowing the ethnographers to become deeply immersed in different social contexts to monitor and study the teens in their practices. However, to define a standard strategy for the local teams, it was more effective to begin with high-schools as the place to delimit the fieldwork. Entering the field through the setting of a high-school made it possible: a) to ensure that the different target socio-cultural environments in each country were covered; b) to engage the teachers in the research process; and c) to guarantee the parents' informed consent as well as the teens' informed consent in order to meet European ethical and data privacy requirements. Moreover, the team needed to develop an ethnographic approach that would allow the researchers to work in a school context but explore the teens' informal digital media skills. To overcome this paradox the team worked out an 
methodological strategy to adapt the exploratory method to school settings, opening it to elements of experimental and participatory design, and visual and sensory multimodal methodological approaches as a way to engage teens in creative practices with media (Dicks, Soyinka and Coffey, 2006; Pink, 2014). This situation implied changing the focus groups initially planned to participatory workshops and reformulating the interviews in a more interactive way, including the use of computers and/or smartphones during the interviewing process.

The methodology was designed for working with two different schools and two different age groups (12-14 and 15-18 years old) in eight countries. The schools would be selected according to a theoretical sampling regarding geographical, institutional and sociological criteria specific to each country; such as central-periphery, urban-rural, homogeneous-heterogeneous ethnic composition, private-public, etc. Each group would be composed of about 25-30 students. The ethnographic based methodology was tested in a public high-school in Barcelona in October-November 2015. 18 students and 6 researchers from Universitat Pompeu Fabra and Universitat Oberta de Catalunya participated in testing, developing and evaluating the study method. After the trial, the coordination team produced a Researcher's Kit with a description of the data gathering activities and a series of flexible research protocols to be applied in the rest of the countries (Ardèvol, 2017).

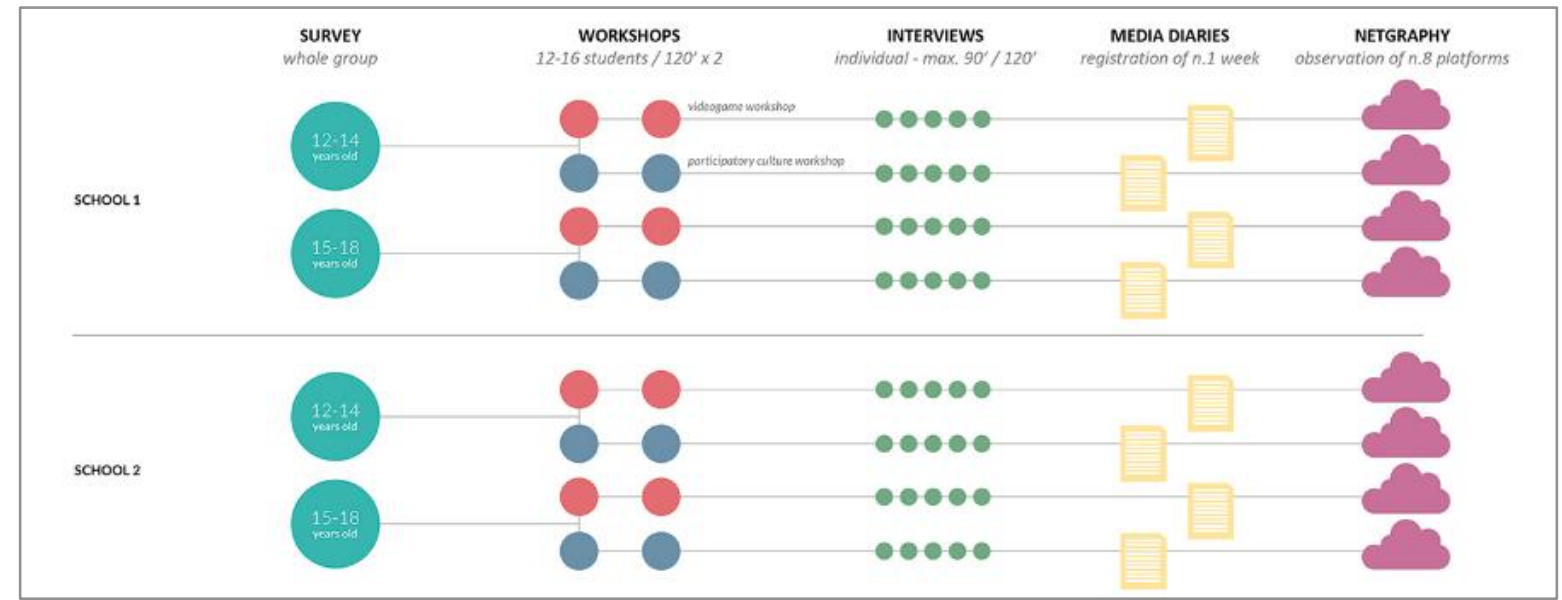

Figure 1: The research strategy. Source: Scolari, 2019

The research strategy was based on a progressive approach that included five procedures: a) Presentation to the school and parents and management of the ethical protocols and informed consent; b) Questionnaire; c) Participatory workshops; d) In-depth interviews and media diaries (Figure n. 1). It is important to highlight that the methodological design took into account that not all the adolescents who agreed to participate in the research project would necessarily participate in all its phases. In other words, the adolescents were asked to participate in the questionnaire and later on, if they wanted to, they could also participate in the participatory workshops; however, only some of them, those who were most motivated and engaged in media production, were asked to participate in the interview and media diaries phase. There was also the possibility that teenagers who used media intensely or in a professional way, or teenagers who were not comfortable talking about their media habits in front of their classmates, would prefer a more intimate context, such as an interview. The previous experience of part of our research team (Lugo Rodríguez, 2016) in carrying out long-term ethnographic studies in schools and the long experience of other members of the research group (Ferrer, Ardèvol, and Parés, 2016) in carrying out visual, sensory and design ethnography was fundamental for this stage of the research. After the research strategy concluded, we decided to add a reflexive observation of the social networking sites that the teens mentioned in the interviews and workshops in order to reach a better understanding of 
the teen's media universes. The team defined this approach as e) netgraphy (see section 3.5), a useful neologism to detach this data gathering technique from any possible connotation or confusion with 'virtual ethnography' (Hine, 2000) or 'online ethnography' or even 'netnography' (Kozinetz, 2009). The difference is because netgraphy does not imply online interaction or participatory research, but rather attentive observation following an ethnographic descriptive and epistemological approach. This part of the research strategy follows a different logic than the others. The questionnaire, the workshops and the interviews are artefacts to produce data, while netgraphy was designed to produce an interpretative context of the teen's practices, sayings and doings during the workshops and the interviews.

Despite the limitations of a school context, the research protocols were developed considering that it is possible to design interventions that favour creativity and participation. Loi and Dillon call these designed interventions 'creative spaces': 'Such designed interventions may involve the use of facilitating technologies and pedagogies that change situational and social dynamics. The potential of digital tools in this context is considered [...] they can be designed to enable people to experiment, contribute, change, design and use the spaces. So conceptualized, they are complex entities where creative expression is defined by interactions between context, people, their practices and their relationships' (Loi and Dillon, 2006:364). Thus, the participatory workshops were designed to create a non-formal environment in which the teens could explore their skills freely and reflect on their interests, practicing what they usually do at home or with friends and schoolmates.

The following paragraphs briefly describe each of these research activities and provide a series of comments and notes about the testing process in the Barcelona high-school. The next sections focus on the above-mentioned four phases as well as the netgraphy or online observation.

\section{a. Presentation to the school and parents and informed consent}

Conducting ethical research with teens involves not only applying an informed consent formula for obtaining approval from ethics committees and review boards, but also an ongoing commitment to researcher thoughtfulness and sensitivity for ensuring the safety, dignity, and expressivity of the teens that participate in the research (Phelan and Kinsella, 2013: 82). In this study, working with schools implied developing a triple consent protocol to include the school, parents and teens that was a compulsory first step before conducting further research. The protocols clearly explained the purposes of the research and that participation was voluntary and could be withdrawn at any time. They also explained the kind of activities the teens would do. In particular, the protocols contemplated five areas of ethical concern: assent or willingness to participate, informed consent and assent using visual methods, issues of disclosure, power imbalances, and audiovisual representations of the teens (Guillemin and Gillam, 2004; Phelan and Kinsella, 2013: 82). It should not be assumed that the informed consent from the school and the young people's parents replaced the consent of the teenagers; the school's and parents' consents were asked to enable the researchers to approach the teenagers for negotiating their participation in the research (Broome and Stieglitz, 1992 quoted in Bray, 2007: 448). The teenagers' consent was sought after written consents from the school and parents or legal guardians were obtained. To obtain the school's and parents' informed consents was not difficult in Barcelona's case because the high-school chosen is very open to education innovation and the teachers saw the proposal as an opportunity to learn more about their students' transmedia skills and informal learning strategies.

\section{b. Questionnaire}

The questionnaire was designed to obtain descriptive statistical data to map the sociological and demographic characteristics of the participants and to get an overview of the teens' practices regarding media uses and creativity. It involved questions about what kind of media they have at 
home, which of them they use frequently, their habits of media consumption, if they share/create content, questions about family control over their media use, privacy management, etc. The questions were organized in five blocks: a) Descriptive socio-demographic questions (sex, age, parents' education, etc.); b) Dichotomous questions of media and device access and use; c) Fivepoint questions (Likert scale) about the time spent doing different media activities (listening, reading, playing, producing, etc.) and the degree of agreement in affirmations; d) Open questions about their main interests and usual uses in relation to media; and e) Their interest in continuing participating in the research.

The questionnaire was a new opportunity to meet the teens after the informed consent session, and a first exchange about their interests that allowed them to decide whether they wanted to be involved in the next stages of the research. The questionnaire also helped researchers to distribute the teens into two workshops, depending on their main interests (see Section 3.3). In this questionnaire the teens were understood to be media prosumers and not just media consumers, an approach that we used throughout the research. The main objective of the questionnaire was not to carry out a representative statistical analysis but rather to obtain socio-demographic data about our sample and to make a first approach to adolescents and an initial exploration of their media uses and preferences.

During the pilot test, we gave the questionnaire to two class groups (all together a total of 18 questionnaires). Beyond the answers, the team observed the teenagers' attitude (doubts that arose, etc.) and asked them whether their media uses were represented in the questionnaire. Some of the teenagers suggested including games or apps that were not in the questionnaire; others were excited with the issues included in the questionnaire because they felt they were being asked about 'things we are really interested in'. In light of the results of the pilot test we modified some points - the team rewrote some questions that were confusing - and the final version of the questionnaire was consolidated.

\section{c. Participatory Workshops}

In the initial proposal the research team planned to organize a series of focus groups with the teens. Later, during the methodology development process, the focus groups were replaced by creative workshops because this technique was considered to be more appropriate for working with teens and more responsive to the objectives of the project. As focus groups are based on verbal speech, they would not be useful for observing practices, while the workshop model allows collaborative participation and creative exploration. Moreover, the workshops were designed as 'ethnographic devices' that provided the opportunity to observe the direct interaction between teens and media, and not just the adolescent's description of his/her media interactions. Workshops were designed as an opportunity for the teens to engage in a meaningful and creative experience (Agud, Novella Cámara, and Llena Berñe, 2014). In this new context, the workshops were intended for:

- Exploring collective understandings, shared practices and values.

- Observing transmedia skills at work (through practices).

- Identifying informal learning strategies.

This second stage of the research was also useful for familiarizing the teens with the research team. The workshops were organized following different steps: 


\begin{tabular}{|l|l|}
\hline Welcome & $\begin{array}{l}\text { Workshop presentation. The participants are introduced to the topic by } \\
\text { viewing a short video. }\end{array}$ \\
\hline Ready to go & $\begin{array}{l}\text { Collective co-creation of a map of their favourites media products or } \\
\text { videogames. }\end{array}$ \\
\hline Hands-on & Creative activity in small groups. \\
\hline Sharing & Presentation and discussion of the productions. \\
\hline Wrapping-up & Assessment and closing of the workshop. \\
\hline
\end{tabular}

Table 2: Participatory workshop structure

Three researchers participated in each workshop. One carried out the general co-ordination of the workshop and served as the main interlocutor with the participants for opening and closing the sessions; the second researcher supported the activities and took field notes; the third one recorded the session (taking a video recording and photos). During the test run the team evaluated the size of the fieldwork team to determine whether three researches in a classroom of 12-16 participants would be too intrusive. The experience demonstrated that it was not a problem per se. On the contrary, first, it allowed the researchers to get to know the teens, which was very positive for the following interviewing process as all the teens knew their future interviewers. Second, the researchers could interact informally with the teenagers in the different stages of the workshop, paying close attention to their different needs and feelings (which would not have been possible for a single researcher). Third, it was very enriching for the three members of the research team to exchange fieldwork impressions, to recall findings and observations and to discuss decisions regarding the next steps of the workshop and the interview process. And last, but not least, it disrupted the school context; that is, it helped to 'break' the typical classroom session by creating an informal environment within a formal institutional setting. The workshop required the use of computers connected to the Internet inside the room; the use of smartphones was encouraged during the sessions.

\section{Narrative Workshop}

The narrative workshop is designed according to three objectives: (a) to map the media consumption of the teenagers; (b) to explore content production and sharing processes; and (c) to identify transmedia skills and informal learning strategies based on their practices. In the pilot phase, the team conducted a two-session narrative workshop with nine participants aged from 14 to 16 years old.

The workshop introduces the goals of the session through a video selection of different media products that are popular with teenagers (i.e. video parodies of TV series, fragments of films made by fans, etc.). Then, the team asks the participants to individually present their favourite products by writing them on post-its to later share them on a collaborative map. In this phase, the teens share their likes and dislikes with the researchers, the values they put on the different media contents, and how they classify them. During the pilot, for example, it was a surprise then for the team that 'video bloggers' appeared as a main genre category, at the same level as 'TV series' and 'films'. Many of the teens considered music and singers as an important media product, alongside books. The mapping process showed how teens categorize their media universe; for example, they perceived 'reality shows' to be in the same category as 'TV series', and one of the groups identified unusual media genres, such as 'suck' for labelling the products that they don't like because they find them revolting or disgusting.

The hands-on phase takes up the largest part of the session. During this phase (see Table $\mathrm{n}$. 2) the group is divided into smaller groups to create a collaborative narrative using any kind of media support. The research team does not participate in the division and creation of the small groups. The teens group together by affinity (usually groups of two to four girls and/or two to four boys) 
and look for inspiration. During the pilot, this phase was really interesting for the researchers because the teens were surfing the Internet using computers or smartphones. The researchers did not give any instructions about how to make the 'creative work' so the participants were on their own, using their own skills without previous guidance. While in some groups the teens quickly discussed their ideas with paper and pencils and other groups opened writing software and began their stories, there were some groups who were apparently 'wasting their time'. They seemed to be 'doing nothing' but looking at their favourite stuff, laughing and talking. After discussing this situation within the research team, it was concluded that these different behaviours had to be respected. On the one hand, the research context should be inclusive, and everyone should be able to participate on their own terms, without feeling frustration. On the other hand, in these informal moments their spontaneous ways of doing, talking and sharing, flourished.

The creation of the narrative takes time. In a workshop of two days, it has to start in the first session and finish in the second session. At the end of the second day each small group has to share their work with the rest of the participants. The research team must not provide any clues or technological tools or software programs to develop this content, thus the result is entirely dependent on the teens' willingness and competencies to produce something during the two sessions of the workshop with the materials at hand. In our pilot experience, one of the small groups did not produce anything at all. One group produced a photo novel by joining pictures from websites and adding speech bubbles, a graphic story that they first worked out on the blackboard and then put together by photographing the scenes. Another group produced a short video vignette and the last one wrote a story in the Wattpad platform (https://www.wattpad.com). In some cases, the computers did not have the software that the teens knew how to use, and this seemed to be a serious problem for the development of the workshop. However, this lack of tools was compensated by the creative strategies of the teens. Although quality work should not be expected from these workshops - the teens do not usually have enough resources (including time) to fully develop their narrative ideas in a two-session workshop - the creative part of this activity can work as an 'ethnographic device' to explore their transmedia skills and competencies related to learning, sharing and solving problems. For example, through this narrative workshop pilot test the research team started to identify some specific transmedia skills related to conceiving the content, producing it and presenting it: knowledge about media genres and formats, the capacity to manage and look for content, information and inspiration, the capacity to plan and take a photo or record a video, the capacity to organize the storytelling of a narrative, the capacity to select the main information from the narrative in order to present it, etc.

To end the workshop, after sharing their creations with their peers and the researchers, the team asks the participants about their social media practices and concerns. Thus, the last part of the workshop is devoted to creating a collective map of the social media the teens use and why they use them. In our case, this social media mapping showed that the teens use different kinds of platforms for different social purposes; for example, Facebook for reading news, for connecting with their distant friends and celebrating family and friends' birthdays; Instagram for following friends and celebrities; Snapchat for having fun with friends; and Whatsapp for coordinating activities with friends and family. They also demonstrated a great knowledge about a lot of apps for different purposes (photo filters, video making, music listening, etc.) and some discussions arose about parental control, safety and privacy. At the end of the two-day workshop the team asks them about their feelings and experiences. The pilot demonstrated that, in general, they were happy and had had fun. Some of the teens told the research team that they were surprised that they could talk about their favourite games and influencers at school. A group of girls said that 'the teachers at school usually think that we know more about media than they do' ('there is nothing they can teach us about media'), but they felt that during the workshop they had learned that they needed 'to learn much more about how to create things with media' and 'to be more thoughtful 
about their use'. They wished the research team could stay longer with them to develop their skills and connect their interests with school tasks.

In general, in methodological terms, the results of the narrative workshop showed that it was appropriate for collecting information on our three objectives. Throughout the different parts of the workshop, the adolescents demonstrated their media use and consumption habits as well as the processes and steps they follow to produce different media content. They displayed the skills they have (or are acquiring) both when they were conceiving the product (looking for references and ideas) and when they were making their own creations (recording, editing, etc.). The narrative workshop was also useful for detecting some learning processes, which were characterized by 'peer-to-peer learning'. The pilot demonstrates that the workshop model works well for uncovering research inferences and hypotheses that should be useful in the analytical phase.

\section{Videogame Workshop}

The videogame workshop was designed according to three objectives: (a) to gather information about the teens' tastes and their consumption habits and routines regarding videogames; (b) to explore their knowledge about videogames and how they acquire it; and (c) to identify their competences and abilities as 'gamers', in terms of how they learn the game's rules and interface functionalities, as well as how they address problem-solving challenges during their gameplay experiences. In the pilot phase, the team conducted a two-session videogame workshop with 9 participants aged from 14 to 16 years old.

In the introductory phase of the workshop, the team shows a brief video with images from several popular videogames that are well known to most teenagers, to encourage an initial, spontaneous conversation on videogames, their preferences, reasons for playing them, etc. Then, in small groups, the team asks them to classify their favourite games into different categories using postits. The researchers can take advantage of this task to carry out informal micro-interviews with the groups as they are working. Thus, the team can explore the teenagers' tastes and implicit cultural hierarchies, viewpoints on different videogame genres, the features that teens particularly appreciate in a videogame, as well as the analytical competences they implicitly show when they talk about and classify videogames.

After this warm-up phase, the hands-on stage (see Table n. 2) consists in a Trivial Pursuit-based creative activity. The objective is to collaboratively create a game centred on videogames, and then play the game themselves. Initially, each group has to choose two topics related to videogames and write 10 to 15 Trivial Pursuit-like questions for each topic. Again, the researchers can 'wander' around the groups as they are developing the questions and engage in informal conversations with them to explore what types of videogames they know best, what videogamerelated topics and aspects are most significant for them and why, and identify possible biases or imbalances regarding the young people's knowledge and competences in gaming.

The second day of the workshop session begins with an introductory activity that consists in a debate moderated by the researchers about the young participants' ways of learning how to play videogames, and how they approach problem-solving when, for example, they get stuck in a game. It is through these discussions that the team may discover the significant role of intergenerational teaching for the participants. In our pilot experience we found that entering the videogame world with the guidance and help of parents and other relatives, and even playing regularly with them, has become quite natural for the current young generations. Interestingly, this fact questions the myth of gamers' parents being a 'resistant' force against videogames. In addition, the use of a PC station with Internet connectivity in the classroom where the workshop was held proved to be a key supporting tool in this activity, since many participants felt motivated to show the websites, 
YouTube channels and YouTube 'star' gamers they usually looked at when they had problems progressing in a given videogame at home. In the end, this revealed a significant and wide 'zone of proximal development' (Vygotsky, 1978) for young gamers, which is a genuine online-transmedia space made up of certain websites, tips'n'tricks forums and YouTube channels. All in all, this activity was crucial for gathering information specifically related to the learning and problemsolving processes of the participants.

Finally, the (most) ludic part of this workshop is when the teenagers, in groups, play the videogame-centred Trivial Pursuit game they have previously 'designed'. In order to complement the knowledge/cultural focus of the question-making activity, the team can add a couple of special features to the game. In our case we added: (1) a special rule so that each time a group gave a correct answer, they had to explain how they learnt it; and (2) a complementary type of question oriented towards a qualitative assessment of the answer (asked by the researchers): questions about 'how do you play - a given game, that the researchers knew was familiar to most of the participants - well?'. With these additional features the team expected to obtain more information on the learning experiences of the young participants; however, they didn't work particularly well, as we explain below.

For the first feature, the participants constantly gave the same, formalistic answer: 'I know it because I've played the game', or 'I learnt it by playing the game'. Though the team failed to foresee this problem, it ended up revealing something interesting: the teens' knowledge about videogame culture seemed to be quite dependent on and/or limited to personal-empirical experience, which was probably symptomatic of certain gaps in videogame literacy, even among young videogame fans, gaps that are not being (properly) addressed in formal/non-formal education so far.

The second complementary feature regarding how a certain game is played well also did not prove to be as fruitful as expected. In this case, the team found that the teenagers had difficulty in rationalizing and verbalizing how a given game (familiar to them) was supposed to be played well. Curiously enough, later on during the interviews, many participants that had shown serious problems in verbally explaining how to play a given videogame well, 'performed' much better with the support of YouTube gameplay videos. This suggests a certain skill gap regarding abstract thinking about videogames, as well as gamers' self-reflection on their own learning processes. The underestimation and absence of videogames in formal education may explain, partly at least, this phenomenon.

Moreover, the young gamers seem to have internalized a hegemonic and 'politically correct' discourse on the social role and value of videogames: when asked about what videogames are useful for, and why do they think they are so significant in their lives, the most common answer, by far, was that videogames 'are a good way to entertain ourselves', just 'a fun way to spend time'. Only when some channelling and 'pushing' questions were asked by the researchers did some considerations about more transcendent values of playing videogames begin to emerge. This led the team to wonder whether a necessary first step to enhancing formal and informal learning through videogames among teens is to make them more aware of the significant skills and abilities they can effectively learn as they play, which in fact they are internalizing day by day as they play videogames as a hobby.

It is important to highlight that, despite the drawbacks detected in the development of the videogame workshop, it was useful for finding adolescents who knew about different videogames and consoles and were able to evaluate their positive and negative points, about playing game modes, rules and playing strategies and about the jargon used in the game community, etc. as well 
as content management skills related to searching and selecting videogame contents or products of interest. Finally, there were skills related to the management of people when gaming as we found teenagers who play together with other teens online and coordinate or lead teams.

The results of this workshop, in methodological terms, were rather unbalanced: it proved to be very useful for gathering information regarding the first two objectives (exploring teens' consumption habits and routines regarding videogames and their knowledge about videogames and how they acquire it), but not so useful (self-sufficient) for achieving the third objective (to identify teens' competences and abilities as 'gamers'). However, this 'weakness' was compensated in the third research phase by the interactive interviews. The research team carried out the interviews next to a PC station so that the participants could show the researchers gameplay videos they already knew via YouTube, which proved to be very useful for exploring how they dealt with personally memorable problem-solving challenges when they played their favourite games.

\section{d. In-depth interviews and media diaries}

The interviews are designed as an enhancement of the workshops to obtain a deeper understanding of teens' transmedia competencies and learning strategies. It is appropriate to select a gender-balanced group of boys and girls who have demonstrated a high level of transmedia skills during the previous sessions and who want to collaborate further in the research. During the week before the interview, the teens are asked to keep a media diary about their daily routines with media. The subject of the interview is designed to cover the young people's preferences in media contents, social media and videogames (what they do with media), how they create and share content and how they like to play videogames (how they do it and with whom), how they learned to play games, to write a post, to upload a photo and who has helped or taught them, and how they share their creations, findings, viewpoints and comments in social media.

Although the researchers would have preferred to interview the teens after school hours, teachers and parents preferred that they were interviewed during school hours in the free and tutorial time. The researchers must adapt to the subjects' needs and requirements, and thus, in the pilot and also in the final protocol, the interviews were conducted at the schools over a couple of days. Three researchers worked in parallel using different available classrooms. In the pilot test we interviewed six teens ( 3 girls and 3 boys).

The interviews are planned to be conducted as an interactive conversation in front of a computer or a smartphone, so the teens can share their experiences with the researchers. As the interviewee may know the researchers from the workshops, the atmosphere should be relaxed and friendly, with the aim that the young person always feels comfortable and cared for (Bray, 2007). The teenagers are also used to the sessions being video recorded from the workshop; thus, it is optional to video record the interviews, placing the camera in a position that does not focus on the teen's face directly, but rather on the keyboard and the screen. During the pilot, the importance of the teens previously getting to know the researchers proved to be fundamental. On the two occasions that the interviewer was not in the same workshop as the interviewee, it was very difficult to establish a good rapport with the teenager, and in one case it was clear that the teen felt very shy, limiting the interaction to short answers, so that the researcher shortened the interview. In all the other cases, the teens were happy to show the interviewers their favourite sites, celebrities, videogames, selfies and other compositions, sharing insights with them for more than one hour. The team wanted them not to be hurried and to take their time to show their online activities, so the interviews were programmed to last two hours. Two hours may seem like a lot of time, but it is better to plan for two hours and just take one hour than end an interview abruptly, taking into account the possibility of kids arriving late, technical problems with devices, difficulties surfing the net looking for favourite games, etc. The average interview time was around 50 minutes, with the kids feeling that they had had enough time to explain their point of view, without 
worrying about finishing the interview on time (the interviews were scheduled sequentially in two days).

The interviews proved to be especially useful for exploring the transmedia skills and informal learning strategies of adolescents. They make it possible to explore in detail the skills related to the audiovisual production and modification and the narrative and aesthetic strategies used to create personal audiovisual products. This is especially true in the case of videogames, as some aspects, which are not possible to detect and investigate in the workshop, can be explored in more detail. In this case, we could observe specific skills related to the problem-solving challenges when playing. During the pilot but also in the implementation of the model at the project level, some teens showed the ability to, for example, be flexible and adaptable when playing, explore the game, and construct characters and build worlds, among others. It was especially interesting to detect some skills related to cheating and breaking the rules in videogames. It was also during the interviews that the researchers were able to delve into the learning strategies carried out by the adolescents. 'Imitation' and 'learning by teaching' were found to be key strategies for learning transmedia skills (Masanet, Guerrero-Pico, and Establés, 2019).

Finally, the media diary is proposed to the teens when the interview is arranged, one week before the interview takes place, so they can keep a media diary during that week and bring it with them to the interview. In this diary the participants can indicate their media activities performed during the day distributed in time bands. The media diary serves to explore the teens' media habits/routines during the week: the organization of media time, the media activities they usually do, differences between school days and weekends, etc. However, many participants of the pilot forgot to do it or didn't feel interested in doing it. Some of the teens brought their media diary with them, and for those that did it, it was a pleasurable experience. Despite this lack of interest, the team decided to keep the diary task as optional during the project research, as it helps to understand the teens' routines and how they manage their free time.

\section{e. Netgraphy}

This is a complementary phase of the research that is carried out after the workshops and the interviews as we realised it was necessary to understand teens' media experiences better. Thus, a non-participant observation of the sites that the teens referred to was necessary to have a firsthand immersion in their universes. A cultural analysis of games and social networking sites makes it possible to contextualise the data both locally and globally. For example, during the interviews in the pilot test, teens told researchers about the YouTube channels they were subscribed to. It has to be said that in 2016 the youtuber world was an unknown universe for adults, like the researchers, as it had no mediatic cover outside youth spheres at that time. Based on the teens' preferences, the team chose the youtuber Auronplay. He is one of the most followed youtubers in Spain, and has 5,021,262 subscribers (March 2017). Following his channel and watching his videos, as teens do, the team became involved in a complex, transnational network of youtubers like Yao Cabrera, a Uruguayan youtuber based in Argentina, and PewDiePie, a YouTube superstar $(54,372,471$ subscribers) involved in a recent controversy with Disney (Solon, 2017). In this case, the team had an enriching experience that helped them to understand what teens meant when they talked about their practices. It helped the researchers to emphatically understand the practices and learning strategies observed or discussed during the interviews. Moreover, to connect researchers' observations with the experience of local teens was crucial for understanding the global phenomena from an ethnographic perspective, and comparing teens' understandings and researchers' findings in a cultural (and critical) analysis. Reflexivity is a driver in ethnography (Hine, 2000; Davis, 2008) and needs to be used as adults face understanding teens' worlds. 


\section{Discussion}

We have outlined the methodological protocol and procedures we developed in order to gather qualitative data with an ethnographic based approach exemplified with our own testing of the designed methods and techniques during the pilot.

It is important to realize that, when working with young people, the first steps of explaining the research aims and obtaining informed consent are very delicate and have to be worked on with a lot of commitment and well in advance. In the Barcelona experience, it took time and patience, and this was also the case during the international research. Countries can vary greatly, not only due to different laws and procedures, but also different cultural backgrounds and expectations. This caused some delays in our research tempos, and some trouble in getting the schools and parents to agree to participate in the research, paradoxically because of the detailed specifications of the informed consent forms and the fact that our study includes audiovisual recordings. In international research initiatives this phase has to be scheduled in advance because it is difficult to harmonize these diverse legal and cultural contexts.

The questionnaire proved to work well as an opening device for the research participants. It provides a first entry to the field and necessary socio-demographic and descriptive data about our sample, but does not provide data that is representative or can be used for statistical based research. Our experience is that the questionnaires are contextual instruments that must be adapted to the diverse countries involved in the research. Our recommendation is that if questionnaires are to be used in international research the items need to be harmonized to the different realities of the countries before the final version is ready to use.

The decision to change from focus groups to participatory workshops had a positive result. In general, the fact that the teens engaged with practical and creative activities in the workshops was a useful source of information about their transmedia practices and knowledge, and thus the workshops provided rich data for identifying skills and learning strategies. To see them 'in action' in an almost informal environment was very important for the team and the research objectives. The workshops were also important for consolidating the relationships with the teens, which allowed us to gain first-hand impressions, inferences and conjectures and helped in preparing the next phase of the research based on the interviews. Making video recordings of the workshop sessions was necessary as the footage provided additional material for later examination and for identifying skills and production/sharing processes.

The video recorded interviews were also very useful as they were transcribed and processed for later content analysis. We must say that all the recorded material and interview transcriptions (researchers' notes, photos, videos, students' productions, media consumption maps, media diaries, etc.) as well as the questionnaires were also subsequently processed with the NVivo for Teams software. In the case of the questionnaires, the data were also processed in a database of the Statistical Package for the Social Sciences (SPSS) program. The analytical work is not explained here as the main subject of this article is to present a model of qualitative data gathering that can be used by multiple international teams at the same time. The fieldwork carried out and tested in the pilot experience proved to be appropriate for achieving the desired objectives: to map the media consumption of the teenagers according to their point of view, to explore content production and sharing processes, and subsequently, to identify transmedia skills and learning strategies. This last objective was only prefigured during the fieldwork, as it was the main task of the data analysis phase (Scolari, 2018 for the results of the study).

Regarding the role of researchers in the workshops, after the first testing session the team found that they needed to be very flexible. For instance, in the narrative workshop the team discussed 
whether the second researcher, the observer, could engage more freely with the participants when they were working on their projects. In this way, the moderator and the observer could both interact and assist participants. The team also noted that it was very important that the visual documenter make students feel comfortable when recording the group work. Some teens wanted to be recorded, others even played with the camera, while others preferred the camera to be directed on their work or further away. The audiovisual recordings of the workshops and the interviews were fundamental components of the methodology for understanding the embodied ways of knowing, the sensory and sensitive domains beyond verbalization (Bayre, Harper and Alfonso, 2016) and also to obtain an evocative resource to connect the fieldwork experience with the data analysis. However, introducing audiovisual recording into the workshops has to be done carefully, always respecting the teens' preferences for appearing or not in front of the camera.

While the workshops did not require specific technologies or devices, in the specific case of the narrative workshop, technology always played a role. As mentioned before, the hands-on activity relied on the available devices (WIFI, mobile phones, tablets, computers, etc); however, the teenagers managed to express their ideas despite technical limitations. For instance, they made a similar version of a 'draw my life' video with very few resources and time. Technology also played a role when the warming-up videos were shown and in sharing the results of the hands-on phase. During the testing the teens found technological alternatives to present and share their productions.

As indicated in the Introduction, the Barcelona testing experience was used to develop the Researcher's Kit (Ardèvol, 2017). The Kit - an operative document that includes a series of research protocols and actions to simultaneously obtain informed consent, and develop and implement the questionnaires, workshops, interviews and media diaries, and the netgraphy in eight countries - was designed as a response to three challenges: 1 ) How to develop an ethnographic strategy so that the researcher can have an immersive experience in the teens' transmedia universe; 2) How to reproduce the fieldwork in different contexts and by different teams; and 3) How to conduct intensive ethnographic research in a relatively short time (Pink and Morgan, 2013). A short reflection before finishing. According to boyd, 'through their experimentation and challenges, today's teens are showcasing some of the complex ways in which technology intersects with society. They don't have all of the answers, but their path through this networked world provides valuable insight into how technology is being integrated into and shaping everyday life' (2014: 211).

Transmedia practices occupy a central space in the techno-cultural experiences that shape teens' everyday life. Although 'what teens are doing as they engage in networked publics makes sense', it is not easy for adults to deal with these practices. boyd concluded that 'coming to terms with life in a networked era is not necessarily easy or obvious. Rather, it's complicated' (28).

Doing research work with teens is also complicated. This article should be considered as a contribution to reducing the complexity involved in answering the question "How can researchers develop an empirical approach and a qualitative methodological strategy to study what teens are doing with media?".

\section{Acknowledgments}

This work emerges from the Transmedia Literacy Project, which has received funding from the European Union's Horizon 2020 Research and Innovation Programme under Grant Agreement No 645238 


\section{References}

Agud, I., Novella Cámara, A. M., \& Llena Berñe, A. (2014). Conditions for Effective Children's Participation, according to Children's Voices. Revista de Cercetare Si Interventie Sociala, 46: 9-21.

Ardèvol, E. (2017). Kit for field researchers. Barcelona. Retrieved from https://repositori.upf.edu/handle/10230/33909

Bayre, F., Harper, K., \& Alfonso, A. I. (2016). Participatory approaches to visual ethnography from the digital to the handmade. an introduction. Visual Ethnography, 5(1): 5-13.

boyd, d. (2014). It's Complicated: the social lives of networked teens. London / New Haven: Yale University Press.

Bray, L. (2007). Interviewing children and young people. Journal of Research in Nursing, 12(5): 447-457.

Bruns, A. (2008). Blogs, Wikipedia, Second Life, and Beyond: From Production to Produsage. New York, NY: Peter Lang.

Buckingham, D. (1993). Towards new literacies, information technology. The English and Media Magazine, Summer, pp. 20-25.

Buckingham, D. (2006). Defining digital literacy. What do young people need to know about digital media?. Digital Komptanse, 4(1): 263-276.

Castells, M. (2007). Estudiar, ¿para qué? (To study, What for?). La Vanguardia, 24/11/2007.

Davis, C. A. (2008). Reflexive ethnography: A guide to researching selves and others. London \& New York: Routledge.

Dicks, B., Soyinka, B., \& Coffey, A. (2006). Multimodal ethnography. Qualitative Research, 6(1):77-96. Doi: $10.1177 / 1468794106058876$

EAVI/DTI/OII (EAVI, Danish Tech Institute, Oxford Internet Institute) (2011). Testing and Refining Criteria to Assess Media Literacy Levels in Europe Final Report. URL: http://ec.europa.eu/culture/media/mediacontent/media-literacy/studies/final-report-ml-study-2011.pdf

Ferrer, J., Ardèvol, E., \& Parés, N. (2016). Ethnography and the quest to (co)design a mixed reality interactive slide. In S. Pink, E. Ardèvol, \& D. Lanzeni (Eds.), Digital Materialities. Design and Anthropology (pp. 115-136). London and New York: Bloomsbury Publishing.

Ferrés, J., \& Piscitelli, A. (2012). Media Competence. Articulated Proposal of Dimensions and Indicators. Comunicar, 19(38), 75-82. https://doi.org/10.3916/C38-2012-02-08

Guillemin, M., \& Gillam, L. (2004). Ethics, Reflexivity, and "Ethically Important Moments" in Research. Qualitative Inquiry, 10(2): 261-280.

Hargittai, E. (2002, April). Second-level digital divide: Differences in people's online skills. First Monday, 7(4). URL: http://firstmonday.org

Haythornthwaite, C. (2007). Social facilitators and inhibitors to online fluency. Proceedings of the 40th Hawaii International Conference on System Science, Waikoloa, HI, 3-6 January.

Hine, C. M. (2000). Virtual Ethnography. Thousand Oaks, CA: Sage Publications Ltd.

Horst, H. A.; Herr-Stephenson, B., \& Robinson, L. (2010). Media Ecologies. In M. Mizuco et al (2010). Hanging Out, Messing Around, and Geeking Out: Kids Living and Learning with New Media. Cambridge (MA): The MIT Press, pp. 29-77.

Jenkins, H. (2006). Convergence Culture. New York: NYU Press.

Jenkins, H., Clinton, K., Purushotma, R., Robison, A., \& Weigel, M. (2006). Confronting the Challenges of Participatory Culture: Media Education for the 21stCentury, Chicago (IL): MacArthur Foundation.

Knobel, M., \& Lankshear, C. (2008). Digital literacy and participation in online social networking space. In: Lankshear C and Knobel M (eds) Digital Literacies, Concepts, Policies and Practices. New York: Peter Lang, pp. 249-278.

Kozinetz, R. (2009). Netnography: Doing Ethnographic Research Online. Thousand Oaks, CA: Sage Publications Ltd. 
Lange, P., \& Ito, M. (2010). Creative production. In M. Ito et al (2010). Hanging Out, Messing Around, and Geeking Out: Kids Living and Learning with New Media. Cambridge, MA: The MIT Press, pp. 243-293.

Leander, K. M. (2008). Toward a connective ethnography of online/offline literacy networks. In: Coiro J, Knobel M, Lankshear C, et al (eds) Handbook of Research on New Literacies. New York: Taylor \& Francis Group, LLC, pp. 33-65.

Lin, Tzu-Bin., Jen-Yi Li, Feng Deng, \& Ling Lee (2013). Understanding New Media Literacy: An Explorative Theoretical Framework. Educational Technology \& Society, 16 (4):160-170.

Livingstone, S. (2004). What is media literacy?. InterMedia, 32(3): 18-20.

Livingstone, S., \& Haddon, L. (2009). EU kids online: Final report. London: London School of Economics and Political Science; EU Kids Online. https://goo.gl/kTYWcK

Loi, D., \& Dillon, P. (2006). Adaptive educational environments as creative spaces Adaptive educational environments as creative spaces. Cambridge Journal of Education, 36(3): 363-381.

Lugo Rodríguez, N. (2016). Diseño de narrativas transmedia para la transalfabetización. Universitat Pompeu Fabra. Retrieved from https://www.tdx.cat/handle/10803/396131\#page=1

Manovich L. (2009). The Practice of Everyday (Media) Life: From Mass Consumption to Mass Cultural Production? Critical Inquiry, 35(2): 319-331.

Masanet, M.-J., Guerrero-Pico, M., \& Establés, M.-J. (2019). From digital native to digital apprentice. A case study of the transmedia skills and informal learning strategies of adolescents in Spain. Learning, Media and Technology, 44(4), 403-413. https://doi.org/10.1080/17439884.2019.1641513

Meyers, E., Erickson, I., \& Small, R. (2013). Digital literacy and informal learning environments: An introduction. Learning, Media and Technology 38(4): 355-367. doi: 10.1080/17439884.2013.783597.

Papacharissi, Z. (ed.)(2010). A Networked Self: Identity, Community, and Culture on Social Network Sites. New York: Routledge.

Phelan, S. K., \& Kinsella, E. A. (2013). Picture This . . Safety, Dignity, and Voice - Ethical Research With Children: Practical Considerations for the Reflexive Researcher. Qualitative Inquiry, 19(2): 81-90.

Pink, S. (2014). Digital-visual-sensory-design anthropology: Ethnography, imagination and intervention. Arts and Humanities in Higher Education, 13(4): 412-427.

Pink, S., \& Ardèvol, E. (2018). Ethnographic Strategies for Revealing Teens' Transmedia Skills and Practices. In C. A. Scolari (Ed.), Teens, Media and Collaborative Cultures. Exploiting Teens' Transmedia Skills in the Classroom (pp. 108-117). Barcelona: Transmedia Literacy H2020 Research and Innovation Action/Universitat Pompeu Fabra.

Pink, S., \& Morgan, J. (2013). Short-term ethnography: intense routes to knowing. Simbolic Interaction, 36(3): 351-361.

Potosky, D. (2007). The internet knowledge (iKnow) measure. Computers in Human Behavior 23(6): 337-348.

Scolari, C. A. (2008). Hipermediaciones: elementos para una teoría de la comunicación digital interactiva. Barcelona: Gedisa.

Scolari, C. A. (2009). Mapping conversations about new media: the theoretical field of digital communication. New Media \& Society, 11(6), 943-964. https://doi.org/10.1177/1461444809336513

Scolari, C. A. (2016). Alfabetismo transmedia. Estrategias de aprendizaje informal y competencias mediáticas en la nueva ecología de la comunicación. Telos, 103, 13-23.

Scolari, C. A. (Ed.). (2018). Teens, Media and Collaborative Cultures. Exploiting Teens' Transmedia Skills in the Classroom. Barcelona: Transmedia Literacy. H2020 Research and Innovation Action/Universitat Pompeu Fabra.

Scolari, C. A. (2019). Beyond the myth of the 'digital native'. Adolescents, collaborative cultures and transmedia skills. Nordic Journal of Digital Literacy, 14(3-4), 164-174. https://doi.org/10.18261/issn.1891-943x-2019-03-04-06

Sefton-Green, J. (2006). Report 7. Literature Review in Informal Learning with Technology Outside School. London: Future Media Lab. 
Solon, O. (2017, February 14). Disney severs ties with YouTube star PewDiePie over antisemitic videos. The Guardian. Retrieved from

https://www.theguardian.com/technology/2017/feb/13/pewdiepie-youtube-star-disney-antisemitic-videos

Toffler, A. (1980). The Third Wave: The classic study of tomorrow. New York: Bantam.

van Deursen, A., \& van Dijk, J. (2010). Internet skills and the digital divide. New Media \& Society 13(6): 893911.

van Dijk, J. (2005). The Deepening Divide. Inequality in The Information Society. London: Sage.

Vygotsky, L. S. (1978). Mind in society: the development of higher psychological processes. Cambridge: Harvard University Press 